\title{
POST-IMPACT MECHANICAL CHARACTERIZATION OF HMPE YARNS
}

\author{
Eduarda da Silva Belloni ${ }^{a, b, *}$, Fernanda Mazuco Clain ${ }^{a}$, \\ Carlos Eduardo Marcos Guilherme ${ }^{a, b}$ \\ ${ }^{a}$ Federal University of Rio Grande, Engineering School, Stress Analysis Laboratory, 96203-000, Rio Grande/RS, \\ Brazil \\ ${ }^{b}$ Federal University of Rio Grande, Post Graduation Program in Mechanical Engineering, 96203-000, Rio \\ Grande/RS, Brazil \\ * corresponding author: eduarda.belloni@furg.br
}

Abstract. The present work evaluates the mechanical behaviour of High Modulus Polyethylene (HMPE) yarns after being impacted by sudden axial loads. The influence of loading conditions on the structural integrity of yarns is assessed by tensile, fatigue, and creep tests before and after the impact events. The impact loads were inferred by drop-weight adopting a $300 \mathrm{~mm}$ height and weights corresponding to 4, 5, and $6 \%$ of Yarn Breaking Load (YBL). At $5 \%$ YBL, most specimens fail after the impact, and at $6 \% \mathrm{YBL}$, all specimens fail. The application of $4 \%$ YBL tests results in enhanced creep and fatigue resistances and a decrease in the tensile resistance. Finally, a Scanning Electron Microscopy (SEM) analysis showed that the yarn filaments tend to straighten after the impact, while a decrease in their diameter is noticed due to the longitudinal deformation.

KEYWORDs: Creep resistance, fatigue resistance, impact test, mechanical testing, HMPE yarns.

\section{Introduction}

Synthetic ropes have been widely used in the oil and gas industry to replace the traditional twisted steel wires, because they offer better flexibility, lower friction coefficient, lighter weight, easier handling, and no potential corrosion-related structural damage. The main application of these ropes is for offshore mooring systems [1. However, they can be applied in several other fields, such as mountain climbing, fire rescue, robotics, artificial muscles, and general load-lifting operations.

High Module Polyethylene (HMPE) is a type of synthetic rope with high abrasion, ultraviolet radiation, and chemical resistance due to the absence of aromatic rings, amides, and hydroxyls, providing an inert behaviour to aggressive chemical agents [2]. The most interesting mechanical aspect of this material is its elevated specific strength because of axially oriented long molecule chains. This can be attributed to the gel-spinning manufacturing process, in which a solvent disengages the polyethylene molecules among themselves, and the material is subsequently stretched to a high extent culminating in a macromolecular reorientation and improved tenacity and modulus 3 .

For this reason, when compared to other synthetic ropes with the same diameter, HMPE ropes offer a significantly higher stiffness [4]. It is noticed that the fibre tenacity and modulus decrease at higher temperatures but increase at low temperatures, which perfectly suits offshore mooring lines that are typically moored on marine water at $4^{\circ} \mathrm{C}$. Besides, even though the creep resistance does not figure among the best features of such material, it is possible to improve it by using a branched-based polymer [5].

Taking into account the polymeric nature of synthetic ropes and their structural division into fibres of micrometric diameter, most investigations are experimental [6. Vogwell et al. [7] tested the mechanical behaviour of polymer cables when subjected to impact loads, and demonstrated that the force transmitted to the cable through the free fall of a mass is directly proportional to the ratio of the fall factor $(h / l)$, where $h$ is the height of the fall and $l$ is the length of the cable.

After submitting the cables to successive impact loads, an increase in the axial stiffness was observed on the cable [6, 7]. Davies et al. 8] compared the performance of HMPE and aramid after water aging, showing that the fatigue life of HMPE is superior to the aramid after water immersion, reinforcing its offshore applicability.

Sry et al. [6] studied the post-impact stiffness of HMPE ropes, stating that the stiffness varies after consecutive sudden loads due to the rearrangement of the internal rope structure and the alignment of strands and yarns toward the rope axis. Furthermore, it was possible to achieve a compact woven rope geometry and stable impact response after a pre-load treatment of 3 times the impact load. Northolt et al. [9] also demonstrated that the inner rearrangement of the rope is the main factor to determine its tensile mechanical behaviour. When the tension increases, the fibre's structure becomes more rigid with a smaller angle in the rope's main axis. 

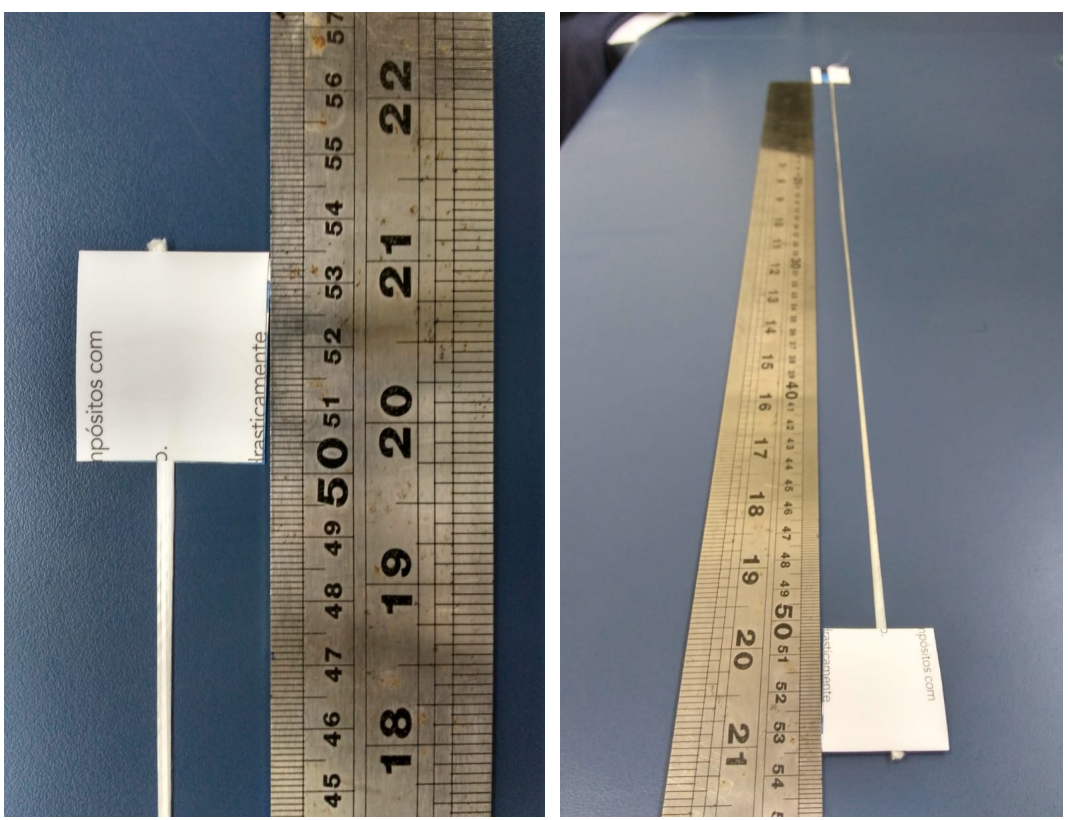

FIGURE 1. Encased specimen samples.

Moreover, similar investigations have shown the mechanical behaviour of the most commonly used synthetic fibres (polyester, polyamide, aramid), assessing creep at low temperatures [10, stiffness [11, and fatigue 1214 of yarns. Within this context, Louzada et al. [15] showed that the fatigue life of polyester yarns decreases after dynamic loadings, depending on the magnitude of the impact.

Aiming to contribute to this complex experimental investigation subject, this work analyses the influence of the impact load on the mechanical behaviour of HMPE yarns through the performance of tensile, fatigue, and creep tests along with a structural SEM analysis.

\section{MATERIALS AND METHODS}

The analysed material consisted of HMPE yarns with a titer of 1764 dtex and $500 \mathrm{~mm}$ long samples with tabs on the ends, as shown in Figure 1. The tabs were necessary to modify the friction coefficient between yarns to achieve an adequate resistance to slippage while testing [16]. The specimens were made immediately before the test in a controlled environment at $20 \pm 2{ }^{\circ} \mathrm{C}$ and $65 \pm 4 \%$ humidity [17, 18].

Initially, 3 tensile tests for the HMPE yarns were realized using an INSTRON 3365 hydraulic universal testing machine adopting a $250 \mathrm{~mm} / \mathrm{min}$ displacement control rate [18]. Then, virgin (i.e. before impact) samples were submitted to dynamic fatigue tests at extreme loading conditions, which is the only attainable case to allow the experiment to be conducted until the specimen's fracture in a timely manner [14. The peak load was set at $90 \%$ YBL as a fixed parameter, whilst 7 trough loads were set from 10 to $70 \%$ YBL considering a $10 \%$ YBL increment [18] as shown in
Table 1 These values were used to simulate extreme load conditions.

Using the INSTRON 8801 testing machine, the initial loading rate was considered as the average of the applied tension per minute with a $0.1 \mathrm{~Hz}$ frequency [19]. To determine the fatigue life, 20 tests were performed for each loading range as shown in Table 1

Creep tests were conducted with the EMIC DL2000 pneumatic testing machine. The samples were submitted to three different static loads of 70, 80, and $90 \%$ YBL and the load was applied by a constant displacement rate of $450 \mathrm{~mm} / \mathrm{min}$. For each parameter, five tests were performed [18.

For the drop-weight impact tests, a drop-weight test tower, previously built in the laboratory, was used, as shown in Figure 2 [15]. To obtain the impact force overtime, a $\pm 10 \mathrm{kN}$ load cell was mounted at the upper end of the equipment with the data acquisition frequency of $5 \mathrm{kHz} 20$. Initial trials depicted $5 \%$ YBL as the terminal load where a failure often takes place. Therefore, a $4 \%$ YBL was chosen to avoid a complete rupture and allowing a post-impact mechanical analysis. Finally, tensile, fatigue and creep tests were performed with post-impacted specimens, and results were compared with those obtained from the virgin samples.

\section{RESUlTS AND DISCUSSIONS}

\subsection{YARN BREAKING LOAD}

The Yarn Breaking Load was defined by performing tensile strength tests. Table 2 shows the average of the results obtained by testing 30 virgin samples. This information was used as a reference for the YBL in subsequent tests. 


\begin{tabular}{cccc}
\hline $\begin{array}{c}\text { Trough load } \\
{[\% \text { YBL }]}\end{array}$ & $\begin{array}{c}\text { Peak load } \\
{[\% \text { YBL }]}\end{array}$ & $\begin{array}{c}\text { Mean load } \\
{[\% \text { YBL }]}\end{array}$ & $\begin{array}{c}\text { Amplitude } \\
{[\% \text { YBL }]}\end{array}$ \\
\hline 10 & 90 & 50 & 40 \\
20 & 90 & 55 & 35 \\
30 & 90 & 60 & 30 \\
40 & 90 & 65 & 25 \\
50 & 90 & 70 & 20 \\
60 & 90 & 75 & 15 \\
70 & 90 & 80 & 10 \\
\hline
\end{tabular}

TABLE 1. Loading ranges analyzed.

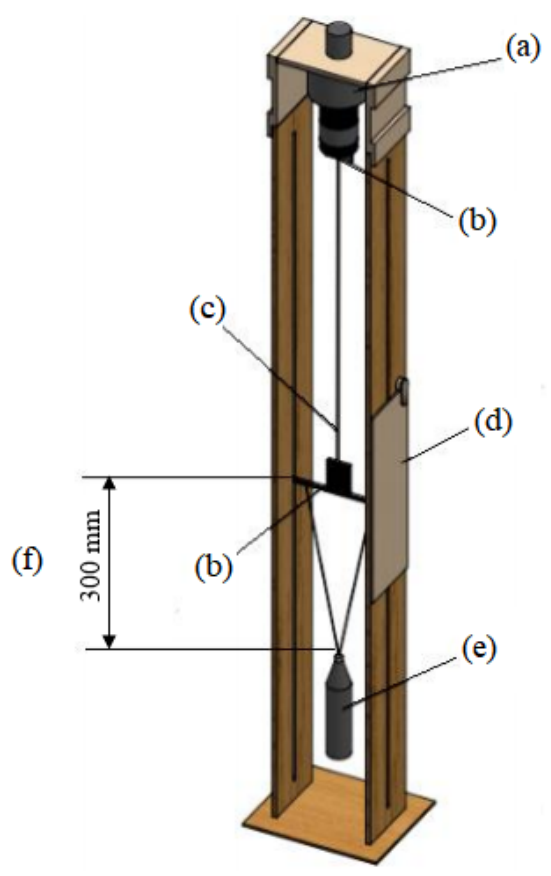

FiguRE 2. Impact machine. (a) Load cell, (b) Terminals, (c) Specimen, (d) Elongation marker, (e) Weight, (f) Free fall height $(300 \mathrm{~mm})$.

\begin{tabular}{ccc}
\hline Material & Tensile Strength [N] & Strain [\%] \\
\hline HMPE & $500.84 \pm 16.37$ & $3.12 \pm 0.08$ \\
\hline
\end{tabular}

TABLE 2. Average tensile strength based on 30 virgin samples.

HMPE has a higher linear tenacity (LT) than other fibres. For example, polyester has an LT of $0.733 \mathrm{~N} /$ tex, whereas HMPE has an LT of $\sim 3 \mathrm{~N} /$ tex. However, a similar behaviour is observed for aramid fibres [1, 14, 15]. HMPE is rigid because of its high macromolecular orientation and crystallinity [3].

\subsection{IMPACT LOAD SETTING}

Table 3 shows the results of impact tests for different loads, shown in terms of percentage of the YBL, from a height of $300 \mathrm{~mm}$. Based on these results, $4 \%$ YBL was chosen because of its low failure rate $(25 \%)$ and its proximity to the limiting threshold of $5 \%$ YBL,

\begin{tabular}{cccccc}
\hline Load [\% YBL] & $3 \%$ & $4 \%$ & $5 \%$ & $6 \%$ & $7 \%$ \\
\hline Failure & 2 & 5 & 14 & 20 & 20 \\
Not Failure & 18 & 15 & 6 & 0 & 0 \\
\hline
\end{tabular}

TABlE 3. Number of impact ruptures for different loads.

where a failure occurred in $70 \%$ of the tests. Figure 3 shows the loads applied to the yarn 21] for 4\%, 5\%, and $6 \%$ YBL loadings.

\subsection{TENSION ANALYSIS}

Figure 4 shows the YBL versus strain at the moment when the YBL is reached for both virgin and impacted HMPE samples. The strain $[\mathrm{mm} / \mathrm{mm}]$ was calculated based on the change in the displacement at the end of the test and the initial sample length. Figure 5 shows that the average tensile stress of the damaged samples decreased, whereas the strain and dispersion increased.

Figure 6 shows virgin and impacted sample images obtained using optical microscopy. The impacted sample in Figure 6 b has ruptured fibres, whereas the virgin sample in Figure 6 a shows no signs of ruptured fibres. Therefore, it can be concluded that the sudden load used in this study was sufficient to rupture the fibres. This phenomenon explains why the tension resistance was diminished. A premature rupture occurs because fewer fibres remain to share the load. This analysis was performed precisely in the middle of the $500 \mathrm{~mm}$-long yarn.

\subsection{Fatigue analysis}

The data obtained in the fatigue tests were subjected to an analysis of variance [22]. The IBM SPSS Statistics 22 software was used for the statistical analysis. Figure 7 shows the number of cycles to failure versus load amplitude for virgin and impacted samples, with notable output differences apparent between the samples. The virgin samples had the best fatigue resistance for $20-90 \%$ YBL loading, whereas the impacted samples endured the maximum number of cycles in the $40-90 \%$ YBL loading range. Most postimpacted samples, except the $20 \%$ and $70 \%$ YBL trough load samples, showed an increase in fatigue 


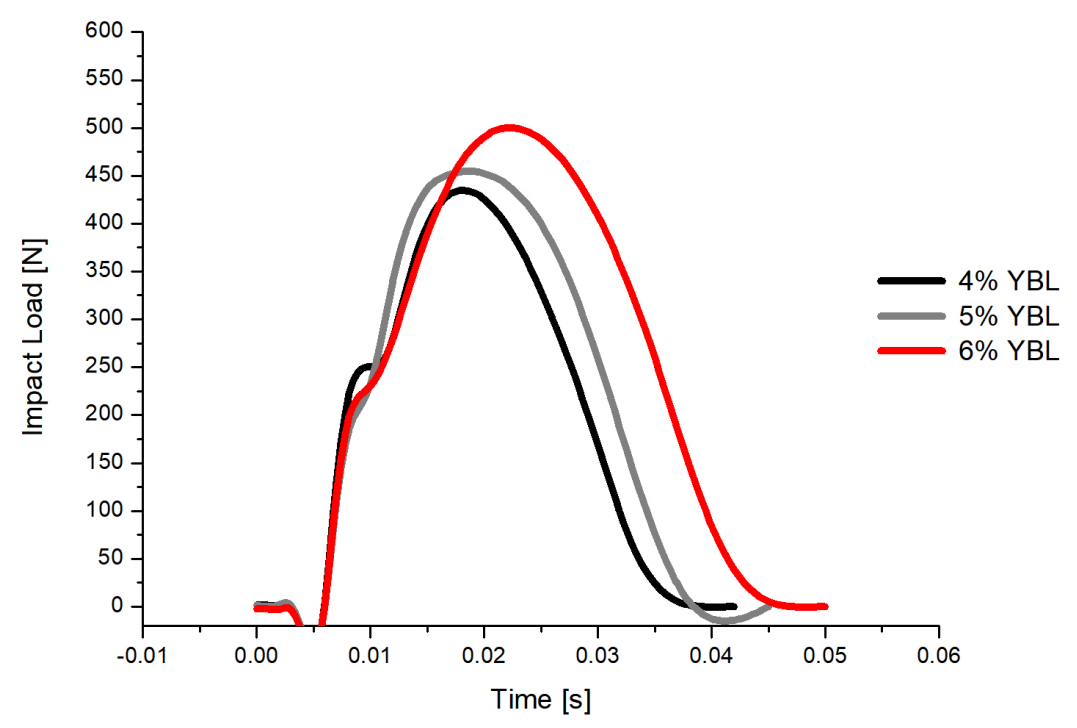

Figure 3. Impact load curves for different loads.

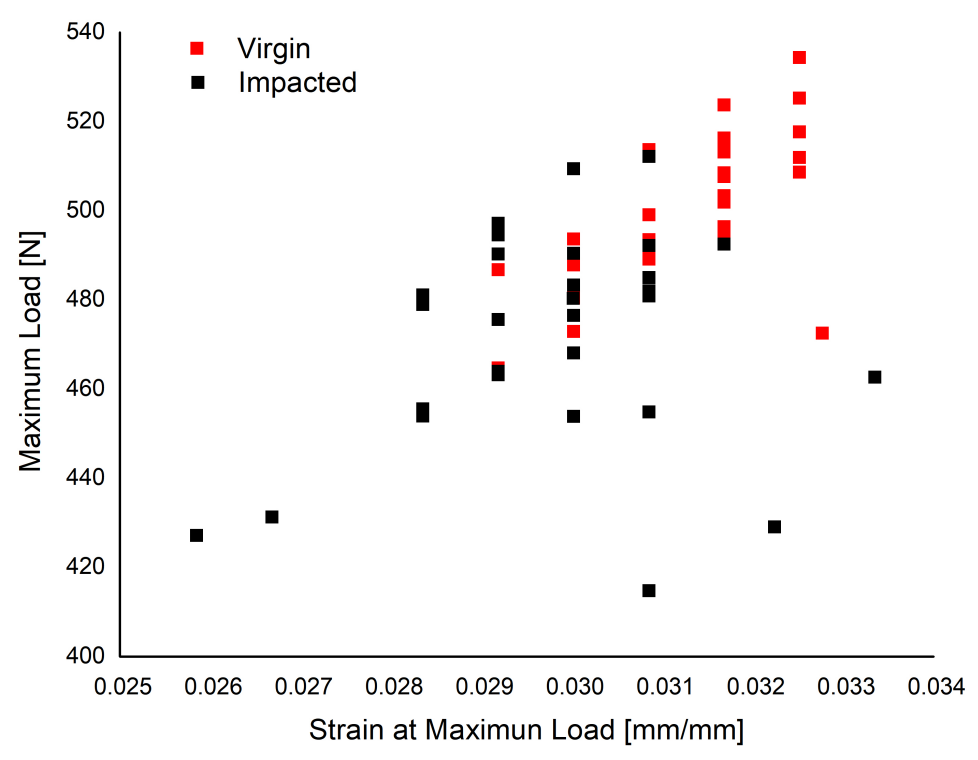

FIGURE 4. Maximum load versus strain for virgin and impacted HMPE samples. 


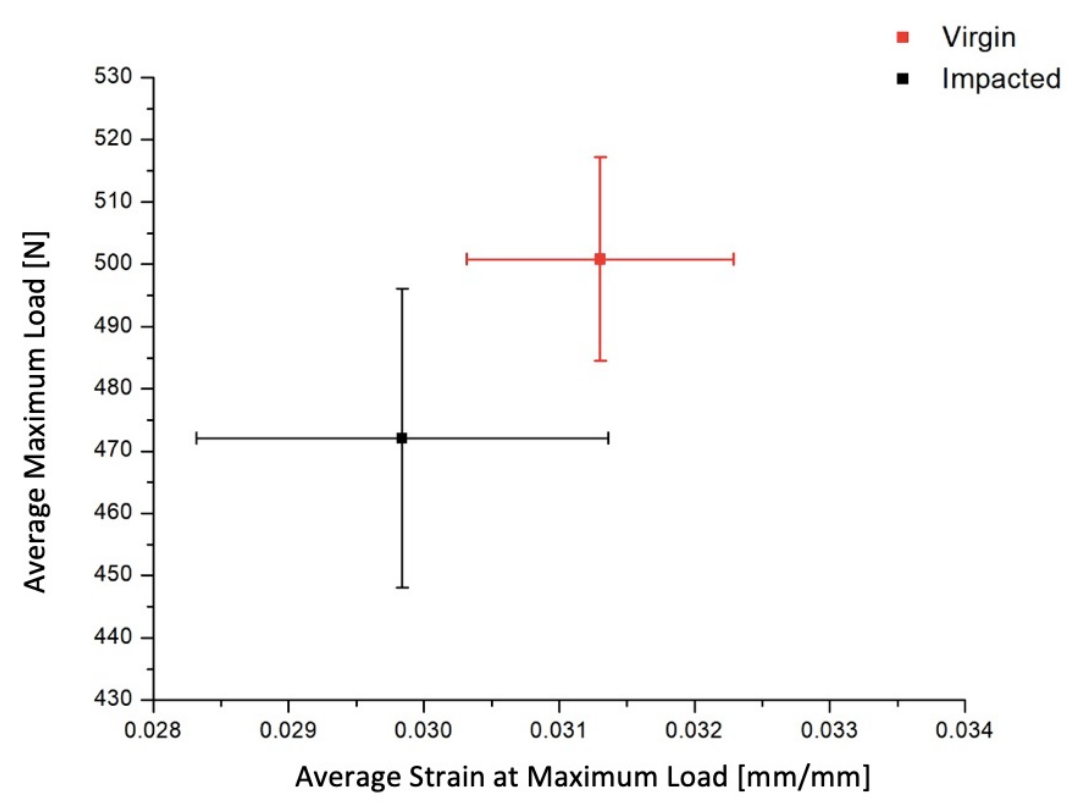

FiguRE 5. Average maximum load versus strain for virgin and impacted HMPE samples.
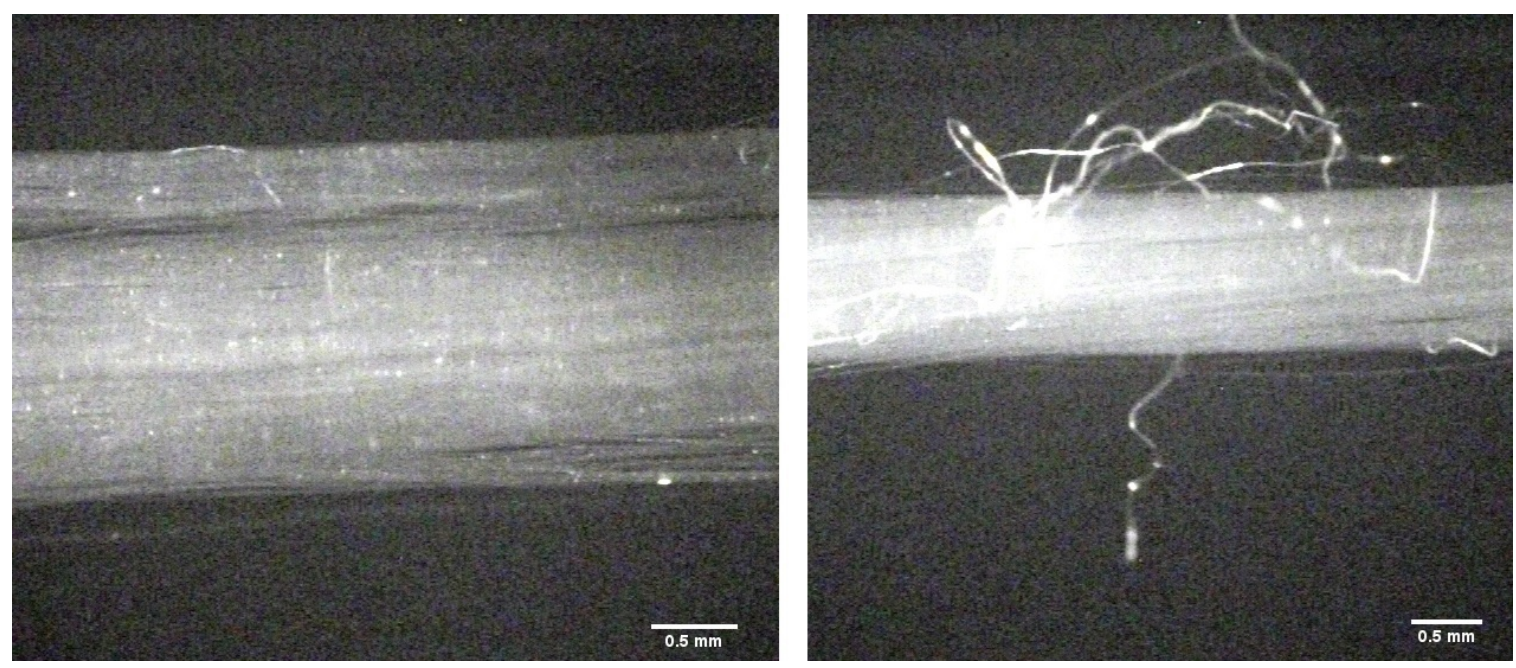

Figure 6. Optical microscopy images of (a) virgin and (b) impacted samples.

life. Table 4 summarizes the number of average cycles to failure for both cases.

\subsection{CREEP ANALYSIS}

For the $70 \%$ and $90 \%$ YBL loads, the time to rupture and stiffness of the impacted samples increased. For an $80 \%$ YBL load, the time to rupture decreased but the stiffness increased. The specific deformation of the virgin and impacted samples did not show a significant variation. In addition to the individual curves for each creep load, Figure 8 shows a comparison for different loads using a logarithmic time scale on the x-axis, whereas Figure 9 compares the extension and time at the creep rupture for all cases.

\subsection{SEM ANALYSIS}

The yarn was ruptured and degraded after the impact and its length increased because of the axial tension applied to each fibre during the impact. In addition,
SEM revealed a decrease in diameter in the impacted fibres, as shown in Figures 10 and 11.

In addition to the diameter measurements in the above figures, 20 measurements were performed in different portions of the specimens. Table 5 lists the average values obtained.

\section{Conclusions}

This study demonstrates that the mechanical behaviour of a material changes when it is subjected to impact loads. Average YBLs of 500.84 and $472.05 \mathrm{~N}$ for virgin and impacted materials, respectively, were obtained from tensile tests. From the fatigue tests, an increase in resistance was found for most loading ranges in post-impacted specimens, underlining the distinguished superiority of $40-90 \%$ YBL loading. This is most likely due to the fibre reorientation improvement during the impact. In addition, no mean- 


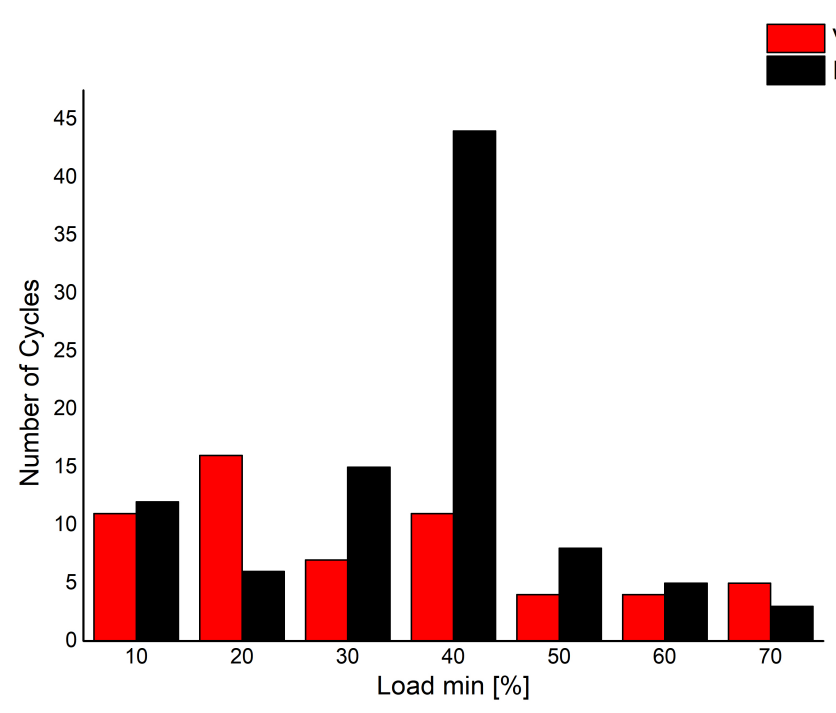

FiguRE 7. Number of cycles to fatigue rupture for virgin and impacted samples.

\begin{tabular}{cccccccc}
\hline Trough Load (\%YBL) & $10 \%$ & $20 \%$ & $30 \%$ & $40 \%$ & $50 \%$ & $60 \%$ & $70 \%$ \\
\hline Virgin & 11 & 16 & 7 & 11 & 4 & 4 & 5 \\
Post-impact & 12 & 6 & 15 & 44 & 8 & 5 & 3 \\
\hline
\end{tabular}

TABLE 4. Number of cycles to fatigue rupture for a peak load of $90 \%$ YBL.

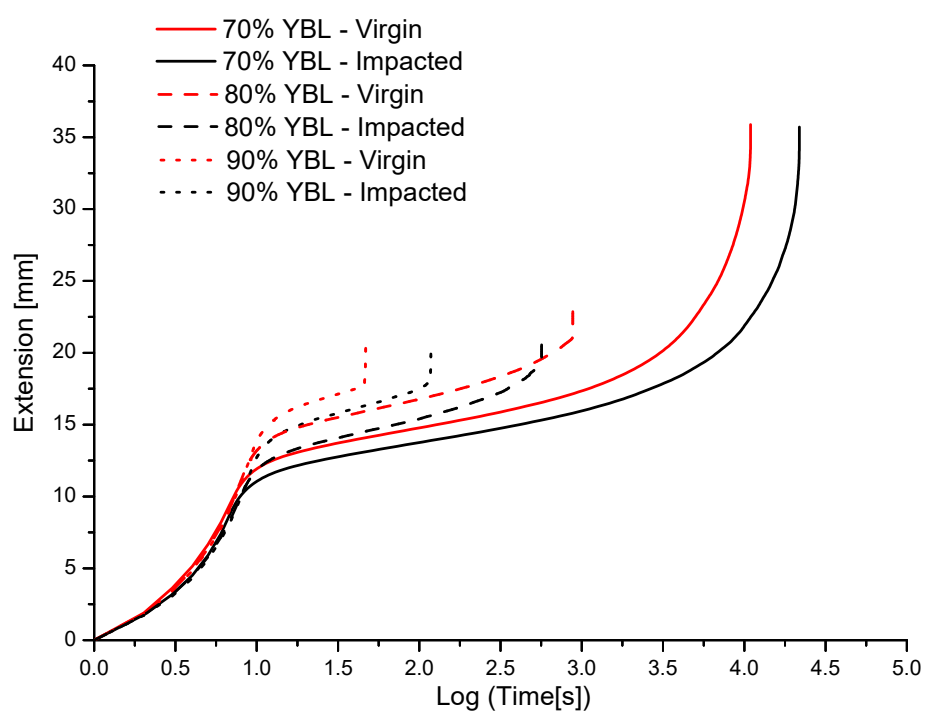

Figure 8. Comparison of creep behaviour for $70 \%, 80 \%$, and $90 \%$ YBL loadings.

\begin{tabular}{cc}
\hline Material & Average diameter $\left[10^{-6} \mathrm{~m}\right]$ \\
\hline Virgin & $17.812 \pm 0.304$ \\
Impacted & $14.666 \pm 0.706$ \\
\hline
\end{tabular}

TABLE 5. Average diameter after impact for virgin and impacted samples. 


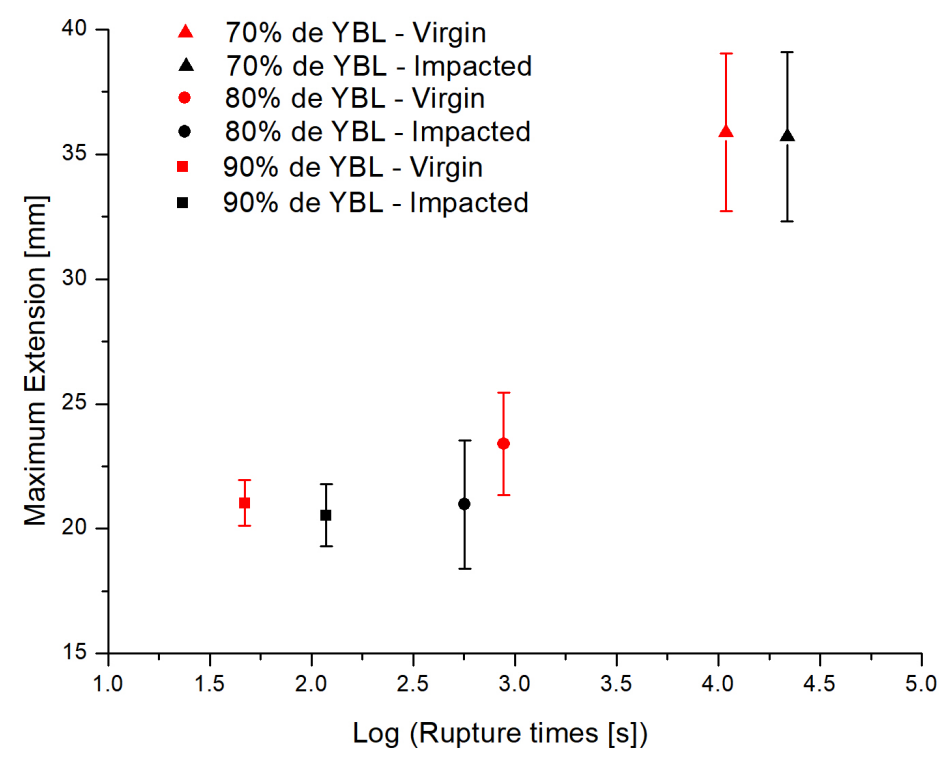

Figure 9. Time and extension at creep rupture for $70 \%, 80 \%$, and $90 \%$ YBL loadings.

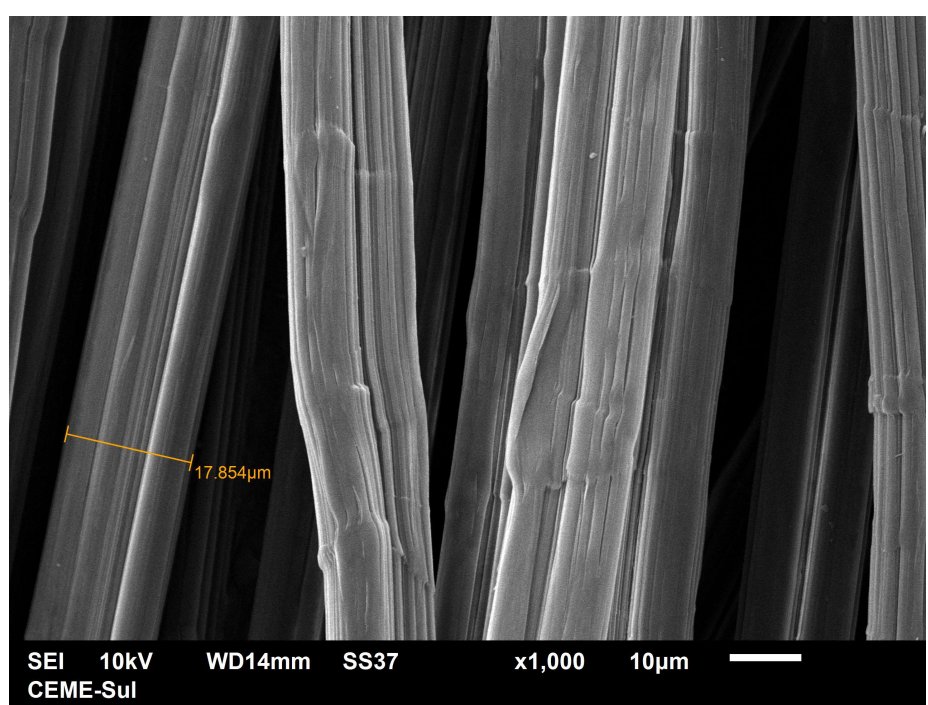

Figure 10. SEM image of a virgin specimen.

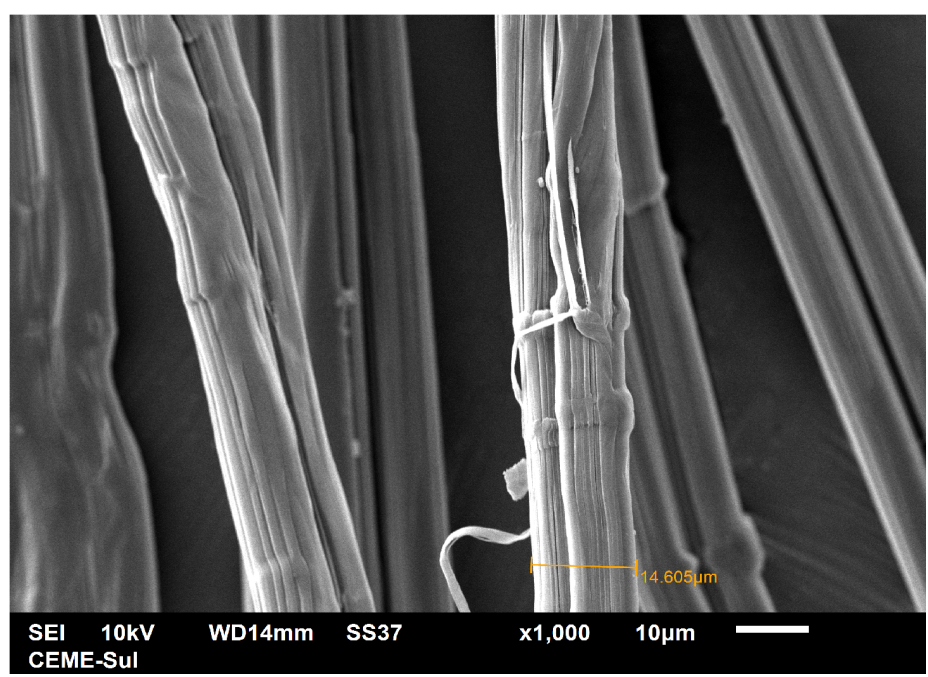

FiguRE 11. SEM image of an impacted specimen. 
ingful relationship between the amplitude and the number of cycles to failure was found.

In the creep tests, the impacted yarns were more resistant to creep at $90 \%$ YBL and $70 \%$ YBL. Moreover, impacted samples presented higher rigidity in all cases, implying that all specimens took more time to reach a certain deformation if they were impacted. It was observed that impacting a yarn with a $6 \%$ YBL-equivalent drop-weight mass from a height of $300 \mathrm{~mm}$ always results in rupture, although $5 \% \mathrm{YBL}$ could already be considered as the critical load for the material because a failure occurred in $70 \%$ of the 20 tests carried out.

Finally, when an impact load ruptures some fibres, the material is degraded, and its tensile strength decreases. However, when fibres do not rupture, the material resistance increases, which is probably triggered by the resulting improved alignment of fibres and multifilament. When this alignment occurs, chemical bonds near the ends of the polymeric chain are much less likely to be broken during a mechanical degradation than bonds closer to the centre of the chain [23]. Moreover, the applied impact load can cause a shear stress-induced plastic orientation [9]. The impact loading could also increase the material stiffness, making it more resistant. In conclusion, a predicted and controlled impact load, as a preload, can improve the properties of yarns and ropes.

\section{ACKNOWLEDGEMENTS}

The authors would like to express their gratitude to FURG and POLICAB for supporting this study, and to the Coordination of Improvement of Higher Education Personnel of the Brazilian Ministry of Education (CAPES/MEC) for the grant $88882.444114 / 2019-01$ that funded the present study.

\section{REFERENCES}

[1] J. P. Duarte, C. E. M. Guilherme, A. H. M. F. T. da Silva, et al. Lifetime prediction of aramid yarns applied to offshore mooring due to purely hydrolytic degradation. Polymers and Polymer Composites 27(8):518 - 524, 2019.

https://doi.org/10.1177/0967391119851386.

[2] C. A. Lopes. Análise de Fluência em Fibra de HMPE para Cabos Utilizados na Ancoragem tipo "Taut Leg" de Sistemas Flutuantes em Águas Profundas. Ph.D. thesis, Federal University of Rio Grande, Brazil, 2003.

[3] J. L. J. Van Dingenen. Gel-spun high-performance polyethylene fibres. In High-performance Fibres, pp. $62-$ 92. 2000 .

[4] L. A. Mohnsan. Simulação numérica do comportamento de cabos viscoelásticos. Ph.D. thesis, Federal University of Rio Grande, Brazil, 2008.

[5] F. M. B. Coutinho, I. L. Mello, L. C. De Santa Maria. Polietileno: principais tipos, propriedades e aplicações. Polímeros 13(1):1 - 13, 2003. https://doi.org/10.1590/S0104-14282003000100005
[6] V. Sry, Y. Mizutani, G. Endo, et al. Consecutive impact loading and preloading effect on stiffness of woven synthetic-fiber rope. Journal of Textile Science and Technology 3:1 - 16, 2017. https://doi.org/10.4236/jtst.2017.31001.

[7] J. Vogwell, J. Minguez. The safety of rock climbing protection devices under falling loads. Engineering Failure Analysis 14(6):1114 - 1123, 2007. https://doi.org/10.1016/j.engfailanal.2006.11.072

[8] P. Davies, Y. Reaud, L. Dussud, P. Woerther. Mechanical behaviour of HMPE and aramid fibre ropes for deep sea handling operations. Ocean Engineering 38(17):2208 - 2214, 2011. https://doi.org/10.1016/j.oceaneng.2011.10.010

[9] M. G. Northolt, J. J. M. Baltussen, B. Schaffers-Korff. Yielding and hysteresis of polymer fibres. Polymer 36(18):3485 - 3492, 1995. https://doi.org/10.1016/0032-3861(95)92020-F

[10] G. S. Husak, F. E. G. Chimisso. Construction of a device to test creep behavior of synthetic multifilaments, submerged in cold water, used in offshore mooring systems and results. In 11th Youth Symposium on Experimental Solid Mechanics, pp. 146 - 151. IMEKO TC15, Brasov, Romania, 2012.

[11] F. T. Stumpf, C. E. M. Guilherme, F. E. G. Chimisso. Preliminary assessment of the change in the mechanical behavior of synthetic yarns submitted to consecutive stiffness tests. Acta Polytechnica CTU Proceedings 3:75 - 77, 2016. https://doi.org/10.14311/APP.2016.3.0075

[12] C. Humeau, P. Davies, P. Smeets, et al. Tension fatigue failure prediction for HMPE fibre ropes. Polymer Testing 65:497 - 504, 2018. https://doi.org/10.1016/j.polymertesting.2017.12.014

[13] P. Davies, M. François, N. Lacotte, et al. An empirical model to predict the lifetime of braided HMPE handling ropes under cyclic bend over sheave (CBOS) loading. Ocean Engineering 97:74 - 81, 2015. https://doi.org/10.1016/j.oceaneng.2015.01.003

[14] F. V. De Camargo, C. E. M. Guilherme, F. Fragassa, et al. Cyclic stress analysis of polyester, aramid, polyethylene and liquid crystal polymer yarns. Acta Polytechnica 56:402 - 408, 2016. https://doi.org/10.14311/AP.2016.56.0402

[15] E. L. V. Louzada, C. E. M. Guilherme, F. T. Stumpf. Evaluation of the fatigue response of polyester yarns after the application of abrupt tension loads. Acta Polytechnica CTU Proceedings 7:76 - 78, 2017. https://doi.org/10.14311/APP.2017.7.0076

[16] J. D. Pfarrius. Theoretical and experimental modeling of a socket sandwich for use in tension tests of synthetic ropes. In 6th Youth Symposium on Experimental Solid Mechanics, pp. 13 - 24. YSESM 07, Vrnjacka Banja, Serbia, 2007.

[17] M. Zoroufi. Significance of fatigue testing parameters in plastics versus metals. In 13th International ASTM/ESIS Symposium on Fatigue and Fracture Mechanics, pp. 37 - 52. ASTM, Jacksonville, United States, 2013. 
[18] ASTM D885:1998. Standard Test Methods for Tire Cords, Tire Cord Fabrics, and Industrial Filament Yarns Made from Manufactured Organic-Base Fibers. Standard, American Society for Testing and Materials, West Conshohocken, 1998.

[19] DNVGL-OS-E303:2010. Yarns for Offshore Mooring Fibre Ropes. Standard, DNV GL, 2010.

[20] BS EN 892:2012. Mountaineering equipment. Dynamic mountaineering ropes. Safety requirements and test methods. Standard, British Standards Institution, London, 2012.
[21] I. Emri, A. Nikonov, B. Zupančič, U. Florjančič. Time-dependent behavior of ropes under impact loading: A dynamic analysis. Sports Technology 1(4 - 5):208 - 219, 2008. https://doi.org/10.1080/19346182.2008.9648475

[22] D. C. Montgomery. Design and analysis of experiments. John Wiley \& Sons, New York, 1st edn., 2013.

[23] K. W. Doak. Ethylene polymers. In H. M. Mark, N. M. Bikales, C. G. Overberg, G. Menges (eds.), Encyclopedia of Polymer Science and Engineering. John-Wiley \& Sons, New York, 1986. 